The INL is a

U.S. Department of Energy

National Laboratory

operated by

Battelle Energy Alliance



\title{
Direct Decomposition of Methane to Hydrogen on Metal Loaded Zeolite Catalyst
}

\section{0th American Chemical Society National Meeting; Ultra-Clean Transportation Fuels Symposium}

\author{
Lucia M. Petkovic \\ Daniel M. Ginosar \\ Kyle C. Burch \\ Harry W. Rollins
}

\section{August 2005}

This is a preprint of a paper intended for publication in a journal or proceedings. Since changes may not be made before publication, this preprint should not be cited or reproduced without permission of the author. This document was prepared as an account of work sponsored by an agency of the United States Government. Neither the United States Government nor any agency thereof, or any of their employees, makes any warranty, expressed or implied, or assumes any legal liability or responsibility for any third party's use, or the results of such use, of any information, apparatus, product or process disclosed in this report, or represents that its use by such third party would not infringe privately owned rights. The views expressed in this paper are not necessarily those of the United States Government or the sponsoring agency. 


\title{
Direct Decomposition of Methane to Hydrogen on Metal Loaded Zeolite Catalyst
}

\author{
Lucia M. Petkovic, Daniel M. Ginosar, Kyle C. Burch, and Harry W. \\ Rollins
}

\author{
Idaho National Laboratory, Idaho Falls, ID 83415-2208
}

\begin{abstract}
The regeneration of a Ru-Mo/ZSM5 catalyst used to produce hydrogen by decomposition reactions was examined at $873 \mathrm{~K}$ in either flowing hydrogen or air. The Ru-Mo/ZSM5 catalyst was deactivated under methane decomposition reaction conditions at temperatures of 873,973 , and $1073 \mathrm{~K}$. The effect of reaction and regeneration conditions on catalyst activity, BET surface area and temperature programmed oxidation profiles is discussed. Regeneration using hydrogen was found to be less effective than air oxidation for the conditions explored. The methane decomposition reactions produced hydrogen primarily through the formation of liquid aromatics. The highest hydrogen production rates were obtained at $1073 \mathrm{~K}$, however, deactivation was greatest at this temperature and the catalyst was not fully regenerated. A better selectivity to liquids combined with a relatively stable catalyst activity indicates that $973 \mathrm{~K}$ may be adequate for longer term catalyst and cycled regeneration analyses.
\end{abstract}

The manufacture of hydrogen from natural gas is essential for the production of ultra clean transportation fuels. Not only is hydrogen necessary to upgrade low quality crude oils to high-quality, low sulfur ultra-clean transportation fuels, hydrogen could eventually replace gasoline and diesel as the ultra-clean transportation fuel of the future. Currently, refinery hydrogen is produced through the steam reforming of natural gas. Although efficient, the 
process is responsible for a significant portion of refinery $\mathrm{CO}_{2}$ emissions. The steam reforming process is capital intensive, owing to the high-temperature, highly endothermic reaction, the need for water gas shift reactors, and gas-gas separation processes. Further, the hydrogen product is contaminated with $\mathrm{CO}$ at concentrations that are detrimental to proton exchange membrane (PEM) fuel cells.

Alternative direct methane conversion chemistries are available that do not produce $\mathrm{CO}_{\mathrm{x}}$ byproducts and offer the potential of lowering capital equipment costs. Methane can be decomposed to produce hydrogen with product formation of carbon, aromatics, or alkene gasses, as represented below.

$$
\begin{array}{ll}
\mathrm{CH}_{4} \rightarrow \mathrm{C}+2 \mathrm{H}_{2} & \Delta \mathrm{H}=75 \mathrm{~kJ} / \mathrm{mol} \\
\mathrm{CH}_{4} \rightarrow 1 / 6 \mathrm{C}_{6} \mathrm{H}_{6}+3 / 2 \mathrm{H}_{2} & \Delta \mathrm{H}=89 \mathrm{~kJ} / \mathrm{mol} \\
\mathrm{CH}_{4} \rightarrow 1 / 2 \mathrm{C}_{2} \mathrm{H}_{4}+\mathrm{H}_{2} & \Delta \mathrm{H}=101 \mathrm{~kJ} / \mathrm{mol}
\end{array}
$$

These reactions are about half as endothermic as the main steam reforming reaction $(\Delta \mathrm{H}=206 \mathrm{~kJ} / \mathrm{mol})$, and, since the carbon value is captured as salable products, $\mathrm{CO}_{2}$ emissions are reduced by at least $80 \%$. However, less hydrogen is produced per unit of natural gas feed, for both reaction and heat requirements. Thus, the value of the carbon based product has a significant impact on the economic viability of the reaction process.

The production of hydrogen from methane over zeolite supported metal catalysts can be examined as an alternative to steam reforming because the concomitant aromatization reactions can increase the economic potential of the process. For methane aromatization, Mo/ZSM5 catalysts have been intensively studied since their first report in 1993 (1, 2). In 1997 (3), the promotional effect of ruthenium over Mo/ZSM5 catalysts was reported. Other second metals have also been studied to improve catalyst activity and stability and a review on this topic is available (4).

Larachi et al. (5) and Iliuta et al. $(6,7)$ compared the conversion of methane over $\mathrm{Ru}-\mathrm{Mo} / \mathrm{ZSM} 5$ catalysts with and without the presence of a $\mathrm{H}_{2}$ permeating membrane and concluded that the availability of $\mathrm{H}_{2}$ helped in the hydrogenation of carbon deposits and hence restoration of catalyst active sites. For the work presented here, it was hypothesized that cycling treatments under flowing $\mathrm{H}_{2}$ might also restore catalyst active sites. Oxidative regeneration under flowing air was also performed for comparison purposes.

\section{Experimental}

A commercially available HZSM5 zeolite (Zeolyst CBV 3020E) was coimpregnated with aqueous solutions of ammonium heptamolybdate tetrahydrate 
(99.98\%, Aldrich) and ruthenium (III) chloride hydrate (99.98\%, Aldrich) by the incipient wetness technique to obtain a final metal content of 3\% Mo and $0.5 \% \mathrm{Ru}$. The material was dried at $393 \mathrm{~K}$ for $2 \mathrm{~h}$. Five hundred milligrams of the dried material were loaded in a tubular quartz reactor, calcined under flowing air (Zero grade, US Welding) for $4 \mathrm{~h}$ at $873 \mathrm{~K}$, then for $0.5 \mathrm{~h}$ at $973 \mathrm{~K}$, and reduced under flowing hydrogen for $0.5 \mathrm{~h}$ at $573 \mathrm{~K}$. The temperature was increased to reaction temperature (i.e., 873,973 , or $1073 \mathrm{~K}$ ) and a flow of 20 $\mathrm{cm}^{3} /$ min of pure methane $(99.99 \%$, Scott Specialty Gases, PA) was initiated. Hydrogen and liquid product yields, as a function of time on stream (TOS), were measured using an on-line Hewlett Packard 5890 gas chromatograph equipped with both FID and TCD detectors and Carboxen 1010 Plot and Petrocol columns. Off-line analysis was performed to quantify ethylene and propylene yields, and to confirm the absence of $\mathrm{CO}_{\mathrm{x}}$ contaminants.

Three sets of experiments were performed to examine the effects of regenerating catalysts with either air or hydrogen: the first set examined the effect of reaction on the catalyst; the second set was used to produce a catalyst sample that had been exposed to both reaction and regeneration; and the last set followed a full cycle of reaction/regeneration/reaction conditions. The first set of experiments was terminated at $3 \mathrm{~h}$ TOS and the spent catalyst recovered. For the second set of experiments, at $3 \mathrm{~h}$ TOS a regeneration step with either 30 $\mathrm{cm}^{3} /$ min flowing air or $20 \mathrm{~cm}^{3} / \mathrm{min}$ flowing hydrogen was initiated. The temperature was set at $873 \mathrm{~K}$ and the gaseous regenerant was flowed through the catalyst bed for 1 hour.

The third set of experiments was performed to determine catalyst behavior after regeneration. For these experiments, after $1 \mathrm{~h}$ regeneration at $873 \mathrm{~K}$, the temperature was set at reaction temperature, and a flow of $20 \mathrm{~cm}^{3} / \mathrm{min}$ of pure methane $(99.99 \%$, Scott Specialty Gases, PA) was initiated again. For the experiments in which the regenerant was air, a 30 min reduction treatment under $30 \mathrm{~cm}^{3} /$ min flowing $\mathrm{H}_{2}$ at $573 \mathrm{~K}$ was applied after regeneration. In all experiments where gas flow was switched from methane to regenerant, or back, the reactor was purged with flowing argon.

Spent catalyst samples were recovered and submitted to ex-situ characterization analyses following the experiments.

B.E.T. surface areas and micropore volumes were determined on a Quantachrome Autosorb 1-C apparatus at liquid nitrogen temperatures. B.E.T. surface areas were calculated in the range of $\mathrm{P} / \mathrm{Po}$ between 0.05 and 0.10 . Micropore volumes were as determined by the t-plot method.

The carbon material deposited on the catalyst was characterized by temperature-programmed oxidation (TPO) on a Perkin Elmer Diamond TG/DTA microbalance under $100 \mathrm{ml} / \mathrm{min}$ flowing air. About $10 \mathrm{mg}$ of sample were placed in the balance pan and heated from room temperature to $373 \mathrm{~K}$ at $10 \mathrm{~K} / \mathrm{min}$. The temperature was kept at $373 \mathrm{~K}$ for $30 \mathrm{~min}$, increased to $1073 \mathrm{~K}$ at $10 \mathrm{~K} / \mathrm{min}$, and then decreased to $373 \mathrm{~K}$. The change in weight between the 
two temperature segments at $373 \mathrm{~K}$ was utilized to report carbon content. The negative of the derivative of weight with respect to time was utilized to obtain the TPO profiles.

Transmission electron microscopy analyses were performed on a Philips EM 420 at $120 \mathrm{kV}$. A small amount of catalyst was dispersed in ethanol and a drop of this dispersion, dried on a carbon-coated copper grid at room temperature, was utilized for the analysis.

Diffuse reflectance infrared Fourier transform spectroscopy (DRIFTS) studies were performed at $373 \mathrm{~K}$ on a Nicolet Magna 750 Fourier transform infrared spectrometer equipped with a commercial Spectratech diffuse reflectance cell. Eight-hundred-scan spectra were collected in the $4000-400 \mathrm{~cm}^{-1}$ range at a resolution of $4 \mathrm{~cm}^{-1}$. The catalyst samples were diluted in $\mathrm{KBr}$ at a ratio of about 1:200 sample:KBr for DRIFTS analyses.

\section{Results and Discussion}

\section{Reaction studies}

Hydrogen and benzene concentrations in the product stream as a function of time on stream (TOS) at different reaction temperatures are shown in Figure 1. Minor amounts (not shown) of toluene, naphthalene, ethylene, propylene, and other aromatics were also found in the product stream. Although formation of carbon oxides at short TOS upon contacting Mo/ZSM5 catalysts with methane has been reported in the literature (8), these products were not detected in any of the gas samples analyzed. Formation of carbon oxides is reported to occur during an induction period in which catalytic active sites are developed by carburization of Mo species. An inverse relation between methane hourly space velocity (MHSP) and induction time has been reported (6). Hence, the absence of carbon oxides even on the first chromatographic sample may be assigned to an induction period shorter than $20 \mathrm{~min}$ due to the relatively larger (i.e., 2400 $\mathrm{mL} /(\mathrm{h} \mathrm{g}))$ MHSP applied here.

As expected from thermodynamic and kinetic considerations, higher initial conversions were seen at higher reaction temperatures. The concentration of $\mathrm{H}_{2}$ was about $5 \%$ at $873 \mathrm{~K}$ and $15 \%$ at $973 \mathrm{~K}$ when fresh catalyst samples were submitted to reaction conditions. Although some decrease with TOS in the production of $\mathrm{H}_{2}$ was seen at those two temperatures, a more pronounced decrease was seen at $1073 \mathrm{~K}$, where $\mathrm{H}_{2}$ concentration changed from about $27 \%$ to $12 \%$. 


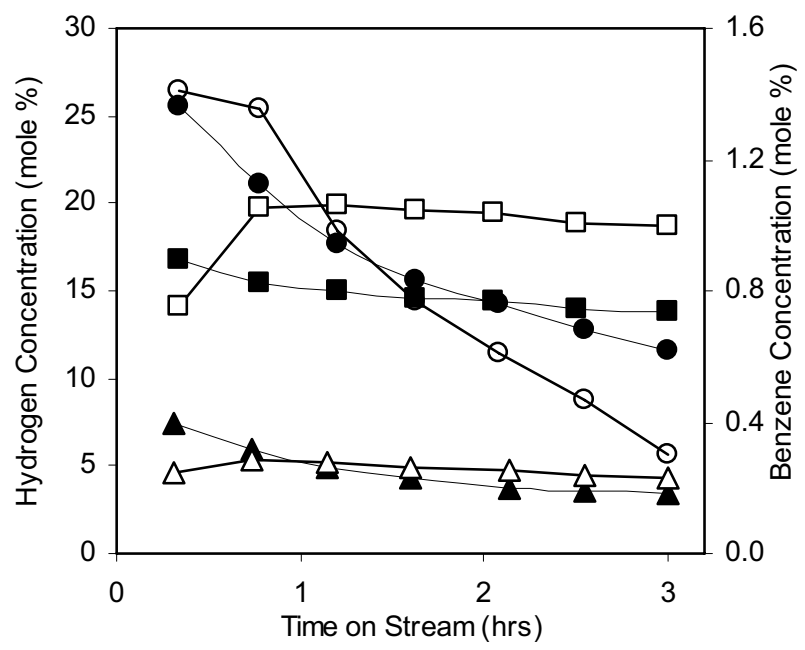

Figure 1. Effect of TOS on hydrogen (filled symbols) and benzene (hollow symbols) concentration in the product stream at 873 (triangles), 973 (squares), and $1073 \mathrm{~K}$ (circles).

The catalyst samples recovered after reaction at 873,973 , and $1073 \mathrm{~K}$ contained 3.1, 4.5, and $11.1 \mathrm{wt} \%$ of carbonaceous deposits, respectively. Assuming a $\mathrm{C}_{1} \mathrm{H}_{1}$ stoichiometry for carbonaceous deposits and adopting average concentrations of aromatics and olefins (i.e., ethylene and propylene), an approximate mass balance was calculated to estimate the contribution of the different reactions to the production of hydrogen. As seen on Table I, at the three temperatures studied, the reactions producing liquid aromatic products accounted for most of the hydrogen produced. It is worth noting that the three chosen reactions are not independent. Aromatics such as benzene are produced by polymerization of ethylene. Further aromatization and dehydrogenation of benzene and higher aromatics contributes to carbonaceous deposits. 
Table I. Percent contribution of different reactions to $\mathbf{H}_{2}$ production

\begin{tabular}{rcccc}
\hline $\begin{array}{l}\text { Reaction } \\
\text { temp. }(\text { K })\end{array}$ & Benzene & $\begin{array}{c}\text { Total liquid } \\
\text { aromatics }\end{array}$ & Ethylene & $\begin{array}{c}\text { Carbonaceous } \\
\text { deposits }\end{array}$ \\
\hline 873 & 49 & 72 & 0.8 & 27 \\
973 & 61 & 87 & 0.7 & 12 \\
1073 & 54 & 67 & 2.8 & 30 \\
\hline
\end{tabular}

\section{Regeneration studies}

After treating the spent catalyst samples with flowing air (see Figures 2 and 3 ), the profiles of $\mathrm{H}_{2}$ and benzene resembled the ones obtained from fresh samples at 873 and $973 \mathrm{~K}$. However, at $1073 \mathrm{~K}$ some loss of activity was apparent.



Figure 2. Effect of regeneration with air on hydrogen yields at 873 (triangles), 973 (squares), and $1073 \mathrm{~K}$ (circles). Filled and hollow symbols correspond to reaction on fresh and regenerated samples, respectively. 


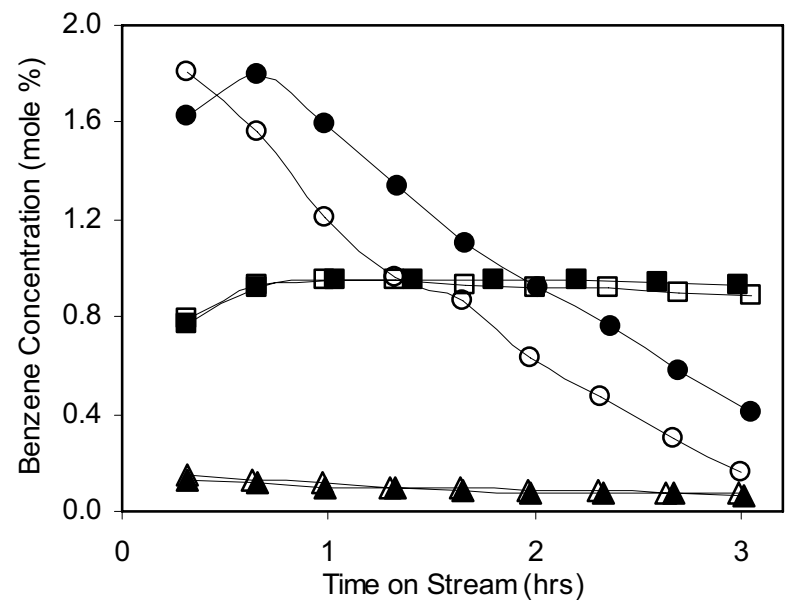

Figure 3. Effect of regeneration with air on benzene yields at 873 (triangles), 973 (squares), and $1073 \mathrm{~K}$ (circles). Filled and hollow symbols correspond to reaction on fresh and regenerated samples, respectively.

Submitting spent catalyst samples to hydrogen treatment was less effective than air treatment as seen in Figures 4 and 5. Working at reaction temperatures of $973 \mathrm{~K}$ or lower, Larachi et al. (5) found that non-carbidic coke formation was reversible and active sites were restored when $\mathrm{H}_{2}$ was available either during off-membrane operation or $\mathrm{CH}_{4} / \mathrm{H}_{2}$ regenerative steps. The results presented here were obtained at higher MHSP and show that the catalyst recovered some activity only at temperatures of 873 and $973 \mathrm{~K}$. However, at the highest temperature of $1073 \mathrm{~K}$, the hydrogen regeneration was not effective, and profiles of $\mathrm{H}_{2}$ and benzene production obtained during the second reaction step (hollow symbols in Figures 4 and 5) seemed to continue the same deactivation trend shown during the first reaction step (filled symbols in Figures 4 and 5).

Table II shows the amounts of carbon deposits as determined by TPO analyses. As reaction temperature increased, the amount of carbon deposits retained on the catalysts increased. Regenerating the spent catalyst with air produced an almost complete elimination of carbon residues. In contrast, regeneration with $\mathrm{H}_{2}$ produced only a partial elimination of deposits. TPO profiles associated with the carbon deposits are shown in Figures 6-8. 


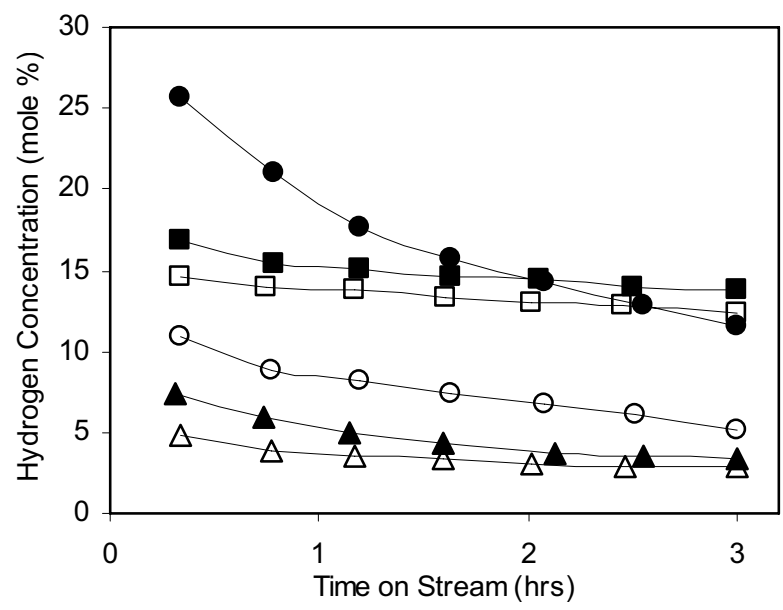

Figure 4. Effect of regeneration with hydrogen on hydrogen yields at 873 (triangles), 973 (squares), and $1073 \mathrm{~K}$ (circles). Filled and hollow symbols correspond to reaction on fresh and regenerated samples, respectively.

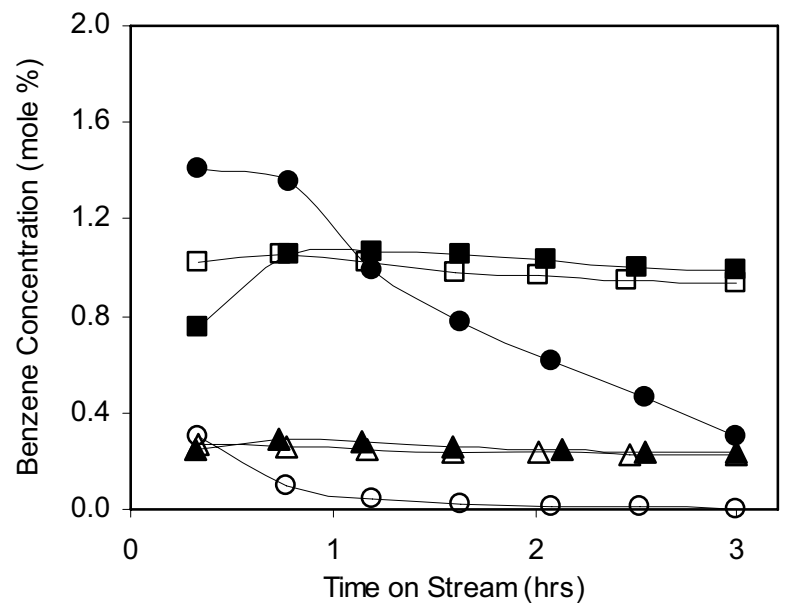

Figure 5. Effect of regeneration with hydrogen on benzene yields at 873 (triangles), 973 (squares), and $1073 \mathrm{~K}$ (circles). Filled and hollow symbols correspond to reaction on fresh and regenerated samples, respectively. 
Table II. Carbon deposits (wt\%) as determined by TPO

\begin{tabular}{rccccc}
\hline $\begin{array}{l}\text { Reaction } \\
\text { temp. (K) }\end{array}$ & $\begin{array}{c}1^{\text {st }} \text { reaction } \\
\text { step }\end{array}$ & $\begin{array}{c}\text { Regener. } \\
\text { with air }\end{array}$ & $\begin{array}{c}\text { Regener. } \\
\text { with } \mathrm{H}_{2}\end{array}$ & $\begin{array}{c}2^{\text {nd }} \\
\text { reaction } \\
\text { after air }\end{array}$ & $\begin{array}{c}2^{\text {nd }} \\
\text { reaction } \\
\text { after } \mathrm{H}_{2}\end{array}$ \\
\hline 873 & 3.1 & 0.6 & 2.8 & 2.0 & 3.6 \\
973 & 4.5 & 0.0 & 3.8 & 4.6 & 4.8 \\
1073 & 11.1 & 0.7 & 5.8 & 9.7 & 13.7 \\
\hline
\end{tabular}

Figure 6 provides a comparison of TPO profiles before and after regeneration in air and hydrogen. TPO profiles for samples that were deactivated at lower reaction temperatures in the first reaction step were shifted to the left (thick lines in Figure 6) indicating that the carbon deposits were easier to oxidize during the analyses. Although this may be ascribed to less condensed hydrocarbons, the lower carbon content may also decrease diffusion limitations that retard the exiting of oxidation products from the zeolitic catalyst.

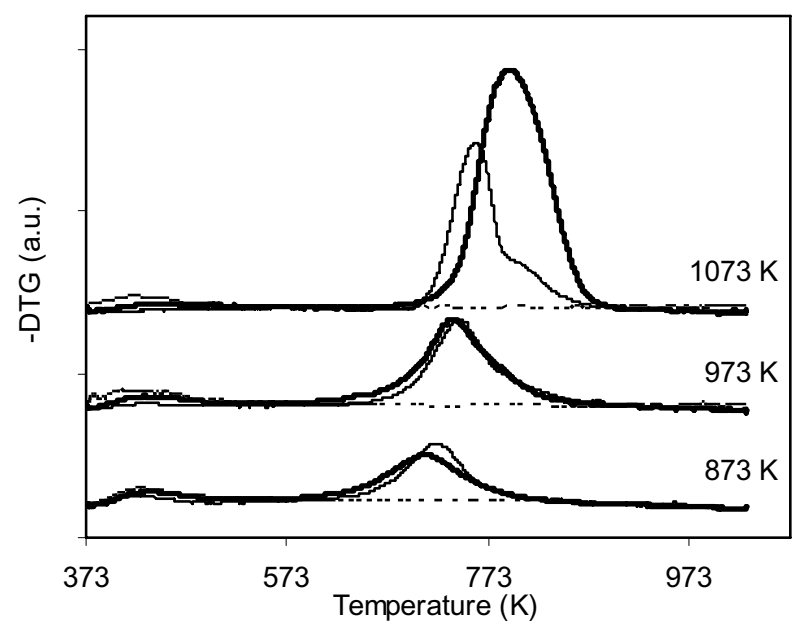

Figure 6. Comparison of TPO profiles before (thick lines) and after regeneration in air (dotted line) and $\mathrm{H}_{2}$ (thin line). Reaction temperature as indicated. 
The TPO profiles of samples that after regeneration were submitted again to reaction conditions are shown in Figures 7 and 8 . When the regenerating treatment was under flowing air (Figure 7), the carbon residues retained during the second time under reaction conditions (thin lines) showed similar TPO profiles as the ones obtained after the first time under reaction conditions (thick lines). However, regenerating the catalyst with $\mathrm{H}_{2}$ seemed to have altered the nature of the residues particularly when the amounts were high. The material still left on the catalyst after $\mathrm{H}_{2}$ regeneration plus the newly retained material during the second reaction at $1073 \mathrm{~K}$ produced a two-peak TPO profile as shown in Figure 8. This indicates that although the regeneration treatment utilizing $\mathrm{H}_{2}$ was not absolutely effective in freeing the catalyst from carbonaceous deposits, it altered the nature of the deposits.

DRIFTS analysis was performed on the spent samples to obtain information on the chemical nature of the carbonaceous deposits retained on the catalysts. The spectra of all samples submitted to reaction and the spectra of samples regenerated under flowing $\mathrm{H}_{2}$ showed a band at $1580 \mathrm{~cm}^{-1}$, which is characteristic of highly condensed hydrocarbons and graphitic-like species. This band was absent on the spectra of samples regenerated under flowing air. C-H stretching bands were hardly noticeable on any spectra which confirm the condensed nature of the deposits.

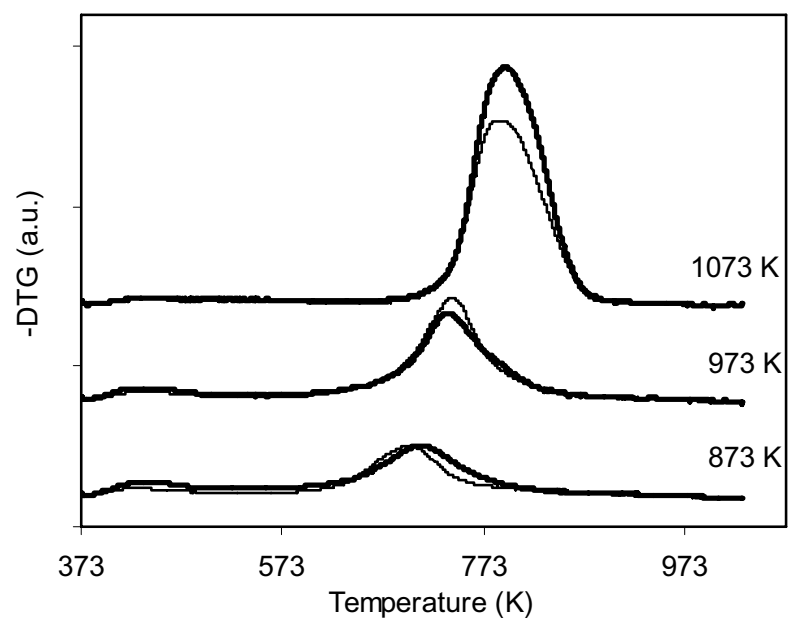

Figure 7. Effect of regeneration with air on TPO profiles. Thick and thin lines correspond to samples submitted once and twice to reaction conditions, respectively. Reaction temperatures as indicated. 


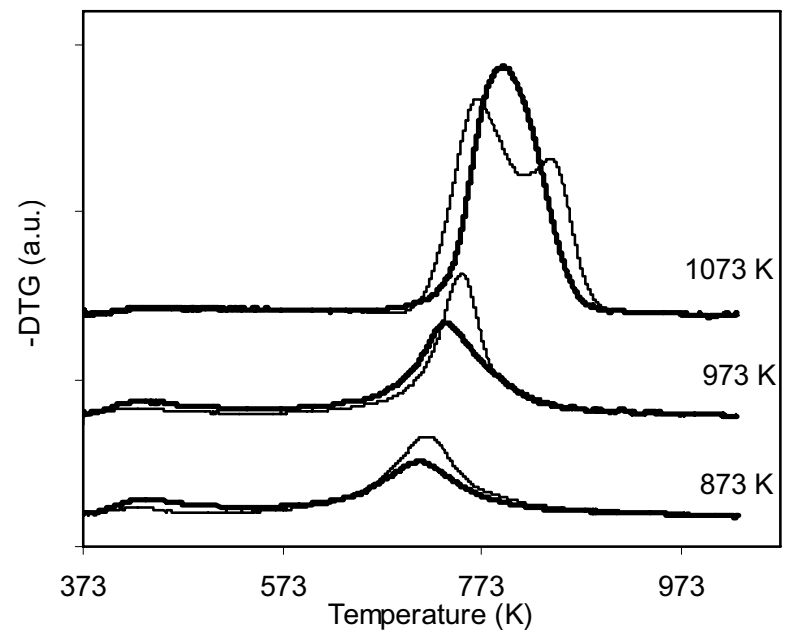

Figure 8. Effect of regeneration with $\mathrm{H}_{2}$ on TPO profiles. Thick and thin lines correspond to samples submitted once or twice to reaction conditions, respectively. Reaction temperatures as indicated.

Transmission electron microscopy analyses showed a homogenous covering of the zeolite surface with carbon deposits. The highly condensed and likely graphitic-type nature of the carbon deposits agrees with the results presented by Larachi et al. (5). These authors identified three carbon-containing species on spent Ru-Mo/ZSM5 by X-ray photoelectron spectroscopy (XPS) analyses. The most prominent peak was assigned to graphitic-like carbon, a weaker peak to aromatic-aliphatic species, and a hardly visible peak to carbidic carbon. As shown by Ding et al. (9), the carbidic carbon is observed on TPO profiles around $500 \mathrm{~K}$ when samples are contacted with methane for only short TOS. After longer TOS only one TPO peak is apparent in agreement with the results presented here.

Table III shows the results of surface area and micropore volume analyses. For the first reaction step higher carbon contents (Table II) were associated with higher losses of surface area and micropore volume, as expected. The fresh sample displayed lower surface area and pore volume than the one utilized at $873 \mathrm{~K}$. This may be due to experimental variability and/or to an actual change in surface area due to changes in the nature of the molybdenum-containing species from oxide to carbide. The highly condensed structure (i.e., likely graphitictype) of the carbon deposits agrees with the measured micropore volumes when 
considering that graphite density is around $2 \mathrm{~g} / \mathrm{cm}^{3}$. For example, a fresh zeolite displaying a micropore volume of $0.12 \mathrm{~cm}^{3} / \mathrm{g}$ would lose about $0.06 \mathrm{~cm}^{3} / \mathrm{g}$ if graphitic carbon deposits reached $11.1 \%$.

Table III. Catalyst B.E.T. surface areas and micropore volumes

\begin{tabular}{cccccc}
\hline $\begin{array}{l}\text { Reaction } \\
\text { temp. }(K)\end{array}$ & $\begin{array}{c}1^{\text {st }} \text { reaction } \\
\text { step }\end{array}$ & $\begin{array}{l}\text { Regener. } \\
\text { with air }\end{array}$ & $\begin{array}{c}\text { Regener. } \\
\text { with } H_{2}\end{array}$ & $\begin{array}{c}2^{\text {nd }} \\
\text { reaction } \\
\text { after air }\end{array}$ & $\begin{array}{l}2^{\text {nd }} \\
\text { reaction } \\
\text { after } H_{2}\end{array}$ \\
\hline 873 & $407(0.13)$ & $392(0.12)$ & $375(0.12)$ & $307(0.09)$ & $316(0.10)$ \\
973 & $310(0.10)$ & $385(0.12)$ & $336(0.11)$ & $307(0.09)$ & $222(0.08)$ \\
1073 & $216(0.07)$ & $375(0.12)$ & $174(0.04)$ & $190(0.06)$ & $46(0.006)$ \\
\hline
\end{tabular}

NOTE: Surfaces areas in $\mathrm{m}^{2} / \mathrm{g}$; micropore volumes in parenthesis, $\mathrm{cm}^{3} / \mathrm{g}$. Fresh sample: $403 \mathrm{~m}^{2} / \mathrm{g}, 0.12 \mathrm{~cm}^{3} / \mathrm{g}$.

Air regeneration produced an important recovery of micropore volume. Even though the amount of carbon deposited during the second step under reaction conditions was about the same or lower, surface areas and micropore volumes were lower than those at the end of the first step. Although some pore plugging might explain these results, it is more likely that irreversible changes in the zeolite structure during air regeneration lead to lower micropore volumes. Rapid burning of carbon deposits by direct introduction of air at such high temperatures has been reported to result in destruction of the ZSM5 crystal structure and complete loss of activity for methane aromatization after succesive air regenerations (10). On the other hand, $\mathrm{H}_{2}$ regeneration was less effective. A decrease in micropore volume was even measured after hydrogen regeneration on the sample initially utilized at $1073 \mathrm{~K}$. This decrease in micropore volume (from 0.07 to $0.04 \mathrm{~cm}^{3} / \mathrm{g}$ ) along with the decrease in carbon content (from 11.1 to $5.8 \%$ ) indicates that the carbon deposits became bulkier/more hydrogenated and/or some pore plugging occurred during regeneration. Pore plugging likely increased during the second step under reaction conditions leading to an almost complete loss of micropore volume by the end of the experiment at $1073 \mathrm{~K}$.

\section{Conclusions}

Although hydrogen production rates were higher at $1073 \mathrm{~K}$, the rapid decrease in catalyst activity, the incomplete activity recovery by either regenerant, and the higher selectivity to carbon deposits makes $1073 \mathrm{~K}$ 
unfavorable for continued or cycled application of this catalyst. A better selectivity to liquids combined with a relatively stable catalyst activity indicates that $973 \mathrm{~K}$ may be adequate for longer term catalyst and cycled regeneration analyses. It is expected that cycled $\mathrm{H}_{2}$ regeneration will be milder with respect to zeolite structure stability when compared with air regeneration but longer term stability and meticulous economic analysis of this process are necessary before any application of this catalyst for production of hydrogen is undertaken.

\section{Acknowledgements}

This work was supported by the U.S. Department of Energy Office of Fossil Energy under DOE Idaho Operations Office Contract DE AC07 05 ID14517.

\section{References}

1. Wang, L.; Tao, L.; Xie, M.; Xu, G.; Huang, J.; Xu, Y. Catal. Lett. 1993, 21, 35-41.

2. Lacheen, H. S.; Iglesia, E. J. Catal. 2005, 230, 173-185.

3. Shu, Y. Y.; Xu, Y. D.; Wong, S. T.; Wang, L. S.; Guo, X. X. J. Catal. 1997, 170, 11-19.

4. Xu, Y.; Lin, L. Appl. Catal. A 1999, 188, 53-67.

5. Larachi, F.; Oudghiri-Hassani, H.; Iliuta, M. C.; Grandjean, B. P. A.; McBreen, P. H. Catal. Lett. 2002, 84, 183-192.

6. Iliuta, M. C.; Larachi, F.; Grandjean, B. P. A.; Iliuta, I. Ind. Eng. Chem. Res. 2002, 41, 2371-2378.

7. Iliuta, M. C.; Grandjean, B. P. A.; Karachi, F. Ind. Eng. Chem. Res. 2003, $42,323-330$.

8. Jiang, H.; Wang, L.; Cui, W.; Xu, Y. Catal. Lett. 1999, 57, 95-102.

9. Ding, W.; Li, S.; Meitzner, G. D.; Iglesia, E. J. Phys. Chem. B 2001, 105, 506-513.

10. Borry, R. W.; Iglesia, E. Proceedings of the Natural Gas Conference, Emerging Technologies for the Natural Gas Industry, P14, March 24 to 27, 1997, Houston, Texas. Available on-line at http://www.netl.doe.gov/ publications/proceedings/97/97ng/ng97_pdf/NGP14.PDF on 12-01-2005. 